016

\title{
IMPIEGO DI UN METODO DI BIOLOGIA MOLECOLARE PER IDENTIFICAZIONE DIRETTA DI Mycobacterium spp.
}

Perandin F., Pinsi G., Signorini C., Gelmi M., Ravizzola G., Manca N.

Cattedra di Microbiologia, U.O. Microbiologia e Virologia, Università degli Studi di Brescia, Spedali Civili di Brescia

\section{Introduzione.}

L'identificazione tempestiva dei Bacilli Acido-Alcol Resistenti (BAAR) è talvolta clinicamente rilevante.

Scopo del lavoro è stato quello di verificare la possibilità d'identificare i micobatteri direttamente dal campione biologico, mediante amplificazione e successiva identificazione con sonde molecolari, impiegando il saggio INNO-LiPA Mycobacteria v.2 (Innogenetics), utilizzato nel nostro laboratorio per identificare i micobatteri da coltura.

Il sistema consente di identificare 22 specie e sottospecie di micobatteri che rappresentano circa il $99 \%$ dei comuni isolati clinici.

\section{Metodi.}

Lo studio è stato condotto su 107 campioni provenienti da sede polmonare ed extrapolmonare, positivi in microscopia per BAAR. L'estrazione del DNA è stata eseguita con il kit "High Pure PCR Template Preparation" (Roche) con le seguenti modifiche: il campione $(500 \mu \mathrm{l})$ è stato centrifugato a $13.000 \mathrm{xg}$ per $15 \mathrm{~min}$; il pellet è stato risospeso in "Tissue Lysis Buffer" e "Proteinase K" e incubato per $1 \mathrm{~h}$ a $55^{\circ} \mathrm{C}$; addizionato con "Binding Buffer" e lasciato a $72{ }^{\circ} \mathrm{C}$ per 30 min. Il DNA purificato è stato sottoposto a PCR (45 cicli) ed ibridazione molecolare, seguendo il protocollo.

\section{Risultati.}

Il sistema di amplificazione applicato direttamente sui campioni biologici ha consentito l'identificazione dei micobatteri nell' $83.2 \%(\mathrm{n}=89)$ dei casi. In particolare, in 81 casi c'è stata concordanza tra $\mathrm{i}$ risultati della coltura e quelli dell'INNO-LiPA; in 26 casi si è avuta discordanza.

Tra questi ultimi, in 18 casi è risultata positiva solo la coltura e nei rimanenti 8 casi è risultato positivo solo INNO-LiPA. Gli ultimi 8 casi comprendono 4 espettorati di pazienti per i quali il clinico aveva già iniziato la terapia prima di inviare $\mathrm{i}$ campioni in laboratorio.

Gli altri 4 si riferiscono a campioni di feci risultati positivi all'INNO-LiPA per $M$. genavense, specie molto esigente dal punto di vista nutritivo.

L'identificazione di questa specie è stata confermata dall'esame colturale eseguito su emocolture inviate contemporaneamente ai rispettivi campioni di feci.

\section{Conclusioni.}

I risultati esposti, anche se relativi ad un numero limitato di campioni, sono di interesse pratico, dato che l'INNO-LiPA non ha dato risultati falsi positivi e ha consentito la diagnosi in 24-36 h.

Sicuramente questo metodo può essere di aiuto per una diagnosi tempestiva anche se non può sostituire gli esami microbiologici convenzionali. 